\title{
Confesión y autenticidad en el discurso populista de hoy
}

Confession and Authenticity in the Current Populist Discourse

Confissão e autenticidade no discurso populista de hoje

\author{
MARIANA VALVERDE **
}

University of Toronto (Toronto, Canadá)

\footnotetext{
* La versión en inglés de este artículo, «Forms of Veridiction in Politics and Culture: Avowal in Today's Jargon of Authenticity», se publicó originalmente en Behemont. A Journal on Civilisation, 11 (2), 96-11. Traducido del inglés por Fernando Avila. Revisado por Felipe Van der Huck. Artículo de reflexión no derivado de investigación recibido el 26.11.2018 y aceptado el 21.02.2019.

** Email: m.valverde@utoronto.ca
} 


\section{Cómo citar}

VALVERDE, MARIANA (2019). Confesión y autenticidad en el discurso populista de hoy. Revista CS, 27, 143-165. https://doi.org/10.18046/recs.i27.3435 
Resumen

Abstract

Resumo

Las formas de populismo político que están floreciendo en todo el mundo, en versiones de extrema derecha, pero también en versiones de izquierda, a menudo se consideran como ignorancia, noticias falsas y demagogia. Sin embargo, ese tipo de análisis a menudo se concentran en el contenido de las afirmaciones de los líderes populistas, sin prestar atención a las formas de «veridicción» y a las prácticas éticas que constituyen el «populismo». Este artículo toma algunas herramientas teóricas de los diversos trabajos de Foucault sobre la «veridicción» y la verdad, y también de la crítica de Adorno al existencialismo, para tratar de comprender las formas y técnicas que constituyen a los líderes populistas como «auténticos», y, de este modo, como cercanos a la gente e incontaminados por instituciones desacreditadas. La autenticidad se crea por medio de formas muy específicas de decir-la-verdad, como se muestra en el ejemplo del fallecido alcalde de Toronto, Rob Ford.

\section{PALABRAS CLAVE:}

populismo, autenticidad, veridicción, Foucault, Adorno

The forms of political populism that are flourishing around the world, in extreme rightwing versions, but also in left-wing versions, are often dismissed as ignorance, fake news, and demagoguery. However, those analyses often focus only on the content of the claims made by populist leaders rather than on the forms of «veridiction» and the ethical practices and forms that constitute «populism». In this article some theoretical tools borrowed from Foucault's diverse work on «veridiction» and truth-telling, and also from Adorno's 196os critique of existentialism, are deployed to try to understand the forms and techniques that constitute populist leaders as «authentic» and thus as close to the people and as not contaminated by discredited institutions. Authenticity is created through very specific forms of truth-telling, as is shown with the example of the late mayor of Toronto, Rob Ford.

KEYWORDS:

Populism, Authenticity, Veridiction, Foucault, Adorno 
As formas de populismo político que estão florescendo em todo o mundo, nas versões de extrema-direita, mas também nas versões de esquerda, são frequentemente consideradas como ignorância, falsas notícias demagogia. No entanto, tais analises geralmente focam-se no conteúdo das reivindicações dos líderes populistas, sem prestar atenção ás formas de «veridicção»e ás práticas éticas que constituem o «populismo». Este artigo utiliza algumas ferramentas teóricas das várias obras de Foucault sobre «veridicção» e verdade, e também da crítica de Adorno ao existencialismo, para tentar entender as formas técnicas que constituem líderes populistas como «autênticos», e, assim, tão perto das pessoas e não contaminado por instituições desacreditadas. A autenticidade é criada através de formas muito específicas de dizer-a-verdade, como mostra o exemplo do falecido prefeito de Toronto, Rob Ford.

PALAVRAS-CHAVE:

populismo, autenticidade, veridicção, Foucault, Adorno 


\section{Introducción}

Los debates entre periodistas, intelectuales y activistas sobre la verdad, la "posverdad» y las formas de subjetividad política no han utilizado bien los abundantes recursos de las largas luchas de la filosofía europea sobre estos temas. Este artículo intentará mostrar que la poco conocida polémica de Theodor Adorno contra las formas filosóficas y populares del discurso existencialista en la Alemania de posguerra -el sarcástico librito titulado La jerga de la autenticidad (Adorno, 1973)-contiene recursos que pueden ser herramientas útiles para ir más allá del viejo binario periodístico «hechos reales» vs. «noticias falsas».

Mientras reflexiona sobre los usos actuales de la polémica de Adorno, el enfoque de este artículo sobre cuestiones de veracidad se basa en gran medida en Foucault. De hecho, el punto de partida del artículo es la insistencia de Foucault de que en vez de tratar de eliminar falsedades para descubrir la verdad -como la filosofía y la ciencia europea han hecho desde siempre, y como los periodistas actuales están profesionalmente obligados a hacer-los intelectuales haríamos mejor en documentar la coexistencia, incluso en el mismo lugar y tiempo, de una variedad de regímenes de verdad y una correspondiente pluralidad de modos de poder. Sin embargo, no usaré la clasificación propia de Foucault de modos de poder/saber (disciplina, gubernamentalidad, etcétera). En cambio, tomo prestado su enfoque, su manera de pensar, para iluminar algunas formas contemporáneas de «veridicción», y explicar cómo cada forma de decir la verdad o decir verdades a alguien promueve prácticas éticas de uno mismo (practices of self) dentro de la cultura popular, el discurso político y el periodismo.

La obra dispersa de Foucault sobre la veridicción (que no se publicó durante su vida ni por mucho tiempo después) juntó el interés en el gobierno de sí mismo desarrollado más sistemáticamente en los volúmenes de La historia de la sexualidad, con las reflexiones inspiradas en Nietzsche sobre la historia de las prácticas de verdad. La palabra «veridicción» (que se inventó Foucault por analogía con el término jurídico «jurisdicción») fue sobre todo elaborada y utilizada en las conferencias impartidas en Lovania en 1981 ante un público criminológico y de derecho penal, publicadas en francés en 2012 y en inglés y español en 2014-un conjunto de conferencias tituladas, por el propio Foucault, Obrar mal, decir verdad: la función de la confesión en la justicia (Foucault, 2014)-. Pero existe una superposición importante entre las conferencias de Lovania y las impartidas en Rio de Janeiro años antes (publicadas en español en 1986 bajo el título La verdad y las formas jurídicas). Las conferencias de Lovania y las de Rio contienen lecturas similares de los mismos textos griegos antiguos-sobre todo, de la tragedia de Edipo Rey-, vista de manera anti-freudiana no como una 
historia de represión psicológica sino como lo contrario, como una historia de la veridicción y de técnicas de buscar, establecer y confesar un tipo de verdades que importa mucho al derecho penal, pero también en contextos políticos-las verdades que revelan algo importante sobre «el obrar mal»-.

Como es sabido, Foucault usaba textos literarios clásicos como recursos para trazar la genealogía de las prácticas de verdad europeas, por ejemplo, «la indagación» que Foucault argumenta que se desarrolló en contextos jurídicos y prejurídicos mucho antes de que fuera adoptada con fines científicos y filosóficos en los siglos XVII y XVIII (Foucault, 200o). Y los que han leído mucho a Foucault saben que hay muchos ecos entre las conferencias sobre la historia de la veridicción de Rio y Lovania, por un lado, y las conferencias dictadas en Berkeley hacia el final de su vida, publicadas en español bajo el título Discurso y verdad (Foucault, 2017). En particular, las reflexiones sobre la parrhesia griega articuladas en Berkeley no hablan explícitamente de «confesión» $\mathrm{o}$ «veridicción», pero centran la atención de modo más general en prácticas de la verdad que, en contraste con tradiciones racionalistas y empiristas, ayudan crucialmente a constituir lo que se podría llamar relaciones personales de veracidad, o relaciones de veracidad personal. La parrhesia asume diferentes formas, pero, en general, la parrhesia griega, nos explica Foucault (que sabía latín y griego por su educación jesuita), es una manera muy social, interactiva y contextual de «decir verdad» («dire vrai» es el término que Foucault usó para traducir el de Nietzsche, Wahrsagen). El «decir verdad» en este sentido expone frecuentemente al que habla a riesgos, ya que las verdades que se dicen son a menudo desagradables o poco favorables para el que escucha (La frase castellana «le voy a decir cuatro verdades» utiliza la palabra verdad en ese sentido).

En estas conferencias Foucault nunca articula un contraste claro entre estas formas de decir verdades a nivel personal e interactivo, por un lado, y los regímenes científicos y filosóficos de verdad estudiados en el inmensamente influyente trabajo foucaultiano de las décadas de 1960 y 1970 sobre las ciencias europeas del «hombre». Pero como he tenido la oportunidad de reflexionar, años después, sobre los heterogéneos estudios de Foucault sobre los juegos de veracidad, puedo decir que el trabajo sobre el «decir verdad» (que, hay que recordar, no se acabó ni se publicó en la vida del autor) llama la atención sobre las prácticas personales de veracidad que crean riesgos para el orador-prácticas que incluyen no solo el «reconocimiento» (aveu, en el francés original), una categoría amplia que incluye la «confesión» y el reconocimiento de una identidad desviada, así como los actos discursivos de lo que se llama en Norteamérica speaking truth to power, «decir la verdad al poder» o «decir cuatro verdades». Si alguien elaborara sistemáticamente esa comparación entre los juegos científicos de veracidad y los juegos de veracidad que son más personales y éticos, 
un punto clave sería que las afirmaciones de verdad científicas se presentan como muy independientes de las relaciones que los expertos puedan tener con colegas, jefes o conciudadanas/os; mientras que en la vida política, en la práctica ética, y para muchos aspectos del derecho penal, lo que cuenta como verdad no es independiente del carácter de las personas involucradas, ni es independiente de sus relaciones.

¿Y todo esto qué tiene que ver con el populismo de ahora? Foucault no comentó nada sobre prácticas actuales análogas al «dire vrai» de los griegos y romanos. Pero es obvio que hay muchos ejemplos de juegos de veracidad que son éticos y personales, no científicos. Por ejemplo, en los tribunales penales de la actualidad se ven «testigos de carácter», personajes a cargo de contar no hechos que vieron con sus propios ojos (esos son los testigos oculares), sino la honestidad o la deshonestidad, la valentía o la cobardía de alguien que ellos conocen personalmente. El testigo de carácter de los tribunales penales del common-law es una de las figuras que ponen de relieve la persistente efectividad de modos de decir-verdad que no solo son diferentes, sino inconmensurables respecto a los de la ciencia. Pero, como veremos, no es necesario restringirse a la anticuada maquinaria epistemológica del common-law (Valverde, 2003) en busca de evidencia para aceptar que el decir-verdad del Foucault tardío ejerce un gran poder a pesar de-o quizá gracias a- su incompatibilidad con las reglas científicas de recopilación y verificación de los hechos. En efecto, el discurso político actual parece estar caracterizado en gran medida por una influencia creciente de formas de veridicción y modos de decir-verdad que giran en torno a categorías no científicas o anti científicas - como la «autenticidad», que, voy a sugerir, es una herramienta clave del discurso político populista-. Las formas de veridicción que se despliegan hoy, a nivel internacional, para construir y luego para validar o invalidar figuras políticas y sociales como «auténticas» es el principal interés de este ensayo.

Puesto que reunir a Foucault y a Adorno es inusual, y esta combinación indigesta de inspiración teórica parece especialmente inadecuada para estudiar formas populares de discurso político, vale la pena señalar como último punto introductorio que Foucault no rechazó ni demonizó la cultura popular de su época, como sí lo hizo Adorno. Foucault evitó expresar de manera explícita el esnobismo de la alta cultura europea -pero de todas maneras es arriesgado utilizar a Foucault para examinar los discursos periodísticos y populares actuales, ya que se abstuvo de hablar sobre las prácticas populares en su propio presente (salvo en algunas entrevistas y en discusiones que, a pesar de haber sido publicadas, tienen un estatus diferente, menos académico, que algunos de sus libros y conferencias formales)-. En su búsqueda de recursos para pensar en «¿cómo podría nuestro presente haber resultado de otra manera?»-la pregunta que une todo el trabajo de Foucault-, Foucault ignoró la investigación antropológica sobre culturas no europeas, así como las investigaciones 
sociológicas sobre subculturas alternativas (y también ignoró el importante trabajo de las feministas de los 70 sobre la historia del cuerpo y la historia de la medicina), prefiriendo hacer, de vez en cuando y generalmente solo en entrevistas, gestos vagos hacia saberes «sumergidos». Por lo tanto, al utilizar el trabajo de Foucault para comprender el discurso político popular de hoy, es necesario advertir que en este ensayo se utiliza el trabajo de Foucault (y el de Adorno) no como modelo teórico, sino como un recurso metodológico para llevar a cabo indagaciones sobre temas que no interesaron a Foucault -o sea, que al usar a Adorno y Foucault como lo estoy haciendo yo misma, estoy «diciendo cuatro verdades» a los maestros y tomando el riesgo de que a los fantasmas de estos filósofos no les gusten nada las «verdades» que yo estoy proponiendo.

\section{Una forma contemporánea de veridicción: verdades personales}

En este ensayo exploro una de las modalidades de lo que Foucault llamó «veridicción», una modalidad que tiene múltiples variedades visibles en el discurso político actual, en el periodismo y en géneros como la televisión de la realidad: el decir verdades «personales». La palabra «personal» no es ideal, porque podría connotar el moderno «yo interior» psicológico cuya genealogía Foucault, y más tarde Nikolas Rose, documentaron cuidadosamente (Rose, $1989 ; 1999)$. Pero no he podido encontrar una palabra mejor, y soy reacia a inventar un neologismo cuando ya hay un término que, a pesar de algunos inconvenientes, puede servir a los fines de un breve ensayo para indicar aproximadamente los límites de mi objeto de estudio.

Las «verdades personales», tal como se utiliza el término aquí, incluyen una amplia gama de declaraciones y reivindicaciones que frecuentemente se superponen con otros modos de veridicción, unos personales y otros empíricos. Y aunque en el análisis el decir-verdad en el sentido de «dire vrai» es muy diferente del establecer hechos con métodos empíricos, algunas, tal vez la mayoría de las declaraciones de verdad personal parecen ser fácticas y, por lo tanto, verificables. Sin embargo, aun cuando se presenten gramaticalmente como enunciados empíricamente verificables, las verdades personales no son principalmente afirmaciones empíricas o científicas. Un buen ejemplo sería la famosa declaración de Richard Nixon «I am not a crook». La semántica es importante. Si uno ha cometido un robo o un fraude, eso es verificable a través de antecedentes penales; pero si se dice que alguien es un «crook» (palabra que indica una persona sin conciencia, haya cometido o no delitos), eso no 
es tan verificable. La designación «crook» difumina la línea que se supone divide las «cuestiones de hecho» de las «cuestiones de interés» (matters offact from matters of concern), para usar el lenguaje de Latour (1999; 2004). En este sentido, la categoría de «crook»-una persona de carácter tramposo-no es ni moderna ni empírica, a pesar de que se superpone con la categoría «delincuente acusado de fraude». Contengan o no afirmaciones empíricas o cuasi empíricas, las afirmaciones de verdad personal también, y de manera crucial, despliegan y se basan en nociones de honestidad/ deshonestidad, coraje/cobardía, honor/deshonor y justicia/injusticia.

Dada la eterna repetición de estos «asuntos de interés» en la cultura occidental -desde el relato de Homero de la carrera de carrozas de Patrocolo (analizada detenidamente por Foucault [2014]) hasta el programa de televisión de Oprah Winfrey-, no es sorprendente encontrar, como muchos comentaristas políticos han subrayado, que las «verdades personales» son las verdades que más importan a la mayoría de la gente. Las personas de la ciencia se preocupan profundamente por los modos empíricos de veridicción; pero las epistemologías científicas no tienen mucha influencia en contextos cotidianos, por ejemplo cuando la gente ve las noticias y decide muy rápidamente si un político es honesto o no.

Más allá de la ciencia, y del periodismo serio, de «hechos», creo que el capital político de hoy se acumula más mediante valoraciones populares y espontáneas del carácter de los políticos que a través de evaluaciones racionales de los datos. Los datos biográficos eran más importantes hace 20 o 30 años; se suponía que para ser elegidos los candidatos tenían que haber demostrado ya, en otros campos, que eran personas serias, con estudios y con experiencia en instituciones importantes. Pero ahora el carácter (que no se puede ver directamente sino solo inferir) parece más importante que los datos del currículo.

El decir-verdad a nivel personal no solo es diferente de los datos empíricos, sino que tiene también una lógica que es muy diferente de la de la autoridad religiosa tradicional. El género de las afirmaciones basadas en la religión ha experimentado en los últimos años un resurgimiento en muchas partes del mundo-un renacimiento o reinvención que no podría haber sido pronosticado durante la vida de Foucault, y que plantea serios desafíos a la narrativa europea (no solo weberiana) de la secularización y la burocratización como fuerzas modernizadoras imparables-. El régimen de verdad religioso contiene una amplia variedad de reglas epistemológicas y prácticas discursivas -tales como la declaración de algunos textos como sagrados y ciertas prácticas cotidianas como impuras, la clasificación de pueblos enteros como condenados o salvados, y la validación de ciertas formas de expresión como inspiradas divinamente $y$, por lo tanto, inmunes a la verificación a través de otras 
epistemologías-. ${ }^{1}$ Sin meterse en detalles sobre el discurso que se apoya en la autoridad revelada, se puede decir que la verdad personal puede funcionar en coalición con la religión organizada, pero también puede funcionar como juego de veracidad autónomo, o sea, en ausencia de una iglesia oficial o de una religión nacional. Probablemente esto explique la popularidad de este género en las sociedades multiculturales contemporáneas. Los personajes políticos y sociales que se presentan como auténticos no son los obispos.

Hay varias estrategias que se pueden utilizar para afirmar verdades personales. Algunas afirmaciones están basadas en prácticas colectivas, a menudo nacionales o étnicas, de solidaridad y memoria. La evocación de victorias y derrotas semi-históricas, semi-míticas, victorias o derrotas narradas con propósitos nacionalistas, como las que Slavoj Zizek analizó en su trabajo sobre la persistencia de la forma ideológica en la era posterior a los contenidos ideológicos (Zizek, 1991), es un excelente ejemplo de la verdad personal colectiva. En Catalunya, por ejemplo, la verdad colectiva de la resistencia contra los Borbones que se acabó en 1714 funciona perfectamente para movilizar a un millón de personas cada 11 de septiembre, así como al Camp Nou casi entero a los 17 minutos 14 segundos de cada partido de fútbol, sin que los catalanes tengan una idea muy clara de los hechos históricos de la guerra de sucesión. Y hay otras formas de veridicción personal que toman una forma colectiva pero no nacionalista, como las actuaciones de los fanáticos incondicionales de equipos deportivos profesionales que no coinciden con la nación o la ciudad.

Pero aquí me voy a concentrar en un tipo de decir verdad personal que no invoca ni el linaje, ni la nación, ni el equipo deportivo, ni cualquier otra colectividad, sino que funciona a nivel de la «persona». Como se mencionaba en la introducción, en el acto de reclamar autoridad para expresar este tipo de verdad, una noción confusa que ejerce gran poder es la de la «autenticidad» (Adorno, 1973). Cuando un programa de televisión declara que una persona invitada al estudio fue elegida porque representa «una voz auténtica» -un tropo común, en el periodismo y en la política- esa designación construye a la persona invitada no como miembro estadísticamente representativo de un grupo, sino como alguien que puede estar hablando de una experiencia colectiva, pero de manera personalizada. El tropo de la «voz auténtica» contrasta implícitamente al individuo que nos habla desde el corazón, sin mediación, y que

1. Al documentar y estudiar regímenes de verdad es importante, en mi opinión, distinguir entre prácticas utilizadas para presentar «hechos» u otras afirmaciones de verdad, por un lado, y las múltiples técnicas que sirven para probar, confirmar, auditar o verificar esas afirmaciones, por otro lado. Lo que dice Foucault (2014) sobre prácticas tales como confesar, testificar y emitir veredictos distingue estas dos dimensiones de los regímenes de verdad, por ejemplo, al señalar que el coro en una tragedia griega desempeña un papel similar al de un jurado en la actualidad. Sin embargo, él no nombra estas dos fases como hago aquí. 
carece de aprobación oficial o institucional, con las actuaciones altamente controladas de voces oficiales, incluyendo expertos, políticos profesionales y representantes oficiales de una religión. No es necesario ser hegeliano convencido para reconocer (como hizo Adorno) que las afirmaciones de autenticidad personal -afirmaciones hechas por la persona misma o por gente como periodistas-dependen del mito del individuo espontáneo que no necesita mediación.

De manera importante (y este es un punto latouriano-foucaultiano que Adorno no aborda), las personas que se presentan como auténticas no amenazan ni cuestionan la autoridad de la ciencia. Simplemente dejan la epistemología científica a un lado. Y tampoco se oponen o desafían directamente a ninguna religión, ni siquiera a la religión en general: sin necesidad de pelearse por la epistemología, estas figuras operan a otra escala y usan criterios diferentes de lo que cuenta como verdad. Una figura contemporánea que ejemplifica esto es la joven pakistaní Malala. El capital político de Malala depende en gran parte de que ella es una persona común -no es una experta o una funcionaria de un gobierno o de otra organización formal-. Sus odas a las virtudes de educar a las jóvenes no occidentales consisten en lugares comunes y banalidades del feminismo liberal y la industria del desarrollo. Pero a pesar de que su discurso es totalmente estereotípico y sin originalidad alguna, ella es famosa porque es «ella misma».

La combinación de un contenido totalmente trillado y una narrativa personal que se presenta como única es precisamente lo que caracterizaba al existencialismo de posguerra, según la polémica de Adorno de 1964 en La jerga de la autenticidad. En un contexto diferente, puede verse hoy en día lo mismo.

En Norteamérica, el movimiento «me too» (yo también) ha lanzado un ejército entero de voces femeninas caracterizadas por la articulación de una individualidad aparentemente única y personal, aunque construida a través de declaraciones de una generalidad abstracta, llenas de lugares comunes ( «los hombres deben respetar a las mujeres»; «la gente deshonesta no debe estar en el gobierno», etc.). Como Malala, las mujeres del «me too» se hacen auténticas al evocar los daños «estructurales» que han sufrido, pero tienen que evocar ese sufrimiento colectivo exclusivamente a través de una narración individual y heroica. Adorno diría que no es casualidad que el movimiento «me too» se llame «me too» y se presente en singular, en vez de usar frases como «nosotras las ciudadanas»o «nosotras las mujeres...».

Un punto genealógico clave respecto a las prácticas actuales de veridicción personal es que los sujetos, o mejor dicho, los objetos de la filantropía organizada de finales del siglo XVIII y principios del XIX (campañas contra la esclavitud, de reforma del trabajo infantil, los principios de salud pública urbana, etc.) fueron presentados como objetos pasivos, casi mudos, de compasión (un ejemplo famoso 
al respecto es La cabaña del tío Tom de Harriet Beecher Stowe). Pero a medida que avanzaba el siglo XIX y especialmente durante el siglo XX, mientras que el objeto mudo de piedad filantrópica sobrevivía (y actualmente prospera en las campañas contra la trata de personas con fines sexuales), muchos de los antiguos objetos de la piedad filantrópica llegaron a ser considerados como al menos potencialmente capaces de hablar. Esto es importante porque, hoy en día, cuando esas voces «subalternas» hablan, o, mejor dicho, son representadas como si estuvieran a punto de hablar (como se ve en los materiales de ONGs que solicitan dinero de países ricos para ayudar a países pobres), sus voces tienen una autoridad especial. Para apreciar esta forma especial de autoridad, este modo de hacer afirmaciones de verdad, es útil releer La jerga de la autenticidad de Theodor Adorno.

\section{Autenticidad y políticas populistas}

La polémica de Adorno explicaba que filósofos como Martin Buber, Karl Jaspers y Martin Heidegger, que idealizaban las interacciones «auténticas», cara a cara, proporcionaron una elaboración filosófica de la cultura dominante de la clase media alemana de posguerra cuyo verdadero fin era evitar discusiones difíciles sobre la responsabilidad histórica de los alemanes. El énfasis en las convicciones personales y el interés en cultivar una subjetividad individual, según Adorno, parecían oponerse a la cultura del consumo capitalista masivo-como se apreciaba en el lamento pastoralista de Heidegger sobre la tecnología-. Adorno argumenta que, a pesar de presentarse como anti-consumo y anti-modernidad tecnológica, tanto el existencialismo filosófico como el popular promovieron un individualismo extremo, un individualismo que solo pudo tomar forma con el capitalismo avanzado. El individuo que se posee a sí mismo (Adorno, 1973: 127) es el mismo promovido por John Locke, el producto de relaciones capitalistas e imperialistas que se imagina a sí mismo como originario, como fuera de y antes de la historia. Y sobre la idea Heidegger de que la autenticidad personal se logra asumiendo el punto de vista del evento más individual de todos, a saber, la «propia» muerte, Adorno comenta: «solo una filosofía solipsista puede reconocer la prioridad ontológica de 'mi' muerte sobre y contra cualquier otra» (Adorno, 1973: 150) -un comentario que por supuesto llama la atención, de una manera no muy sutil, a las conocidas simpatías nazis de Heidegger-.

El filosofar desde el punto de vista de la propia muerte es peculiarmente heideggeriano, pero lo que no es único es la inclinación de Heidegger por idealizar y mitificar la vida concreta y artesanal, supuestamente opuesta al capitalismo de consumo de masas, a pesar de que la filosofía existencialista es precisamente un producto 
cultural del capitalismo avanzado (Adorno, 1973: 89-93). Podemos agregar que una cosa en común entre Heidegger y las exaltaciones populares de la autenticidad personal (que se encuentran casi exclusivamente en géneros periodísticos y de cultura popular, por cierto, dado que el existencialismo ya no se acostumbra en filosofía) es que utilizan un lenguaje altamente abstracto, casi sin contenido, para validar la idea de que hay una verdad especial que viene de la experiencia personal -o mejor dicho de una narración bastante estereotipada de la vida de uno/una misma, vista como un cuento de heroísmo personal-. Hay ejemplos de este discurso por todas partes, desde tarjetas para felicitar a los que se gradúan a lo que dicen los futbolistas cuando ganan una copa: «sé fiel a ti mismo», «vive tu sueño» (live your dream), etc.

La autenticidad es un efecto (efecto social y político, no solo discursivo) producido a muchos niveles y escalas. Por ejemplo, tanto en el Sur global como en el Norte hoy se pueden comprar alimentos «auténticos», productos artesanales cuya aura benjaminiana se genera por contraste con los alimentos de supermercado. En este contexto, hay que recordar lo que dijo Adorno -que las afirmaciones sobre la experiencia auténtica aparentan desafiar la producción en masa capitalista, pero son en realidad los suplementos dominicales que respaldan silenciosamente la cultura del consumo masivo-. Sin embrago, para centrarse en los juegos de la verdad que tienen una relevancia particular para la subjetividad política, es mejor ocuparse no de productos auténticos ${ }^{2}$ sino de identidades políticas auténticas, en línea con el ejemplo de Malala.

\section{Un hombre blanco auténtico en una ciudad cosmopolita y multicultural}

Un ejemplo-entre muchos- de políticos actuales cuyo ascenso dependió de generar una imagen de autenticidad es el del político que fue alcalde de Toronto, Rob Ford. Rob Ford ganó atención mundial cuando admitió públicamente (después de muchas negativas) que había fumado crack de cocaína y, para gran asombro de propios y extraños, luego procedió a explicar su conducta diciendo: «sí, he fumado crack de cocaína... probablemente en una de mis borracheras, one of my drunken stupours». ${ }^{3}$ Esta declaración puede ser vista como un acto particular de la autenticidad -obviamente muy diferente de la de Malala-. (En general, la autenticidad femenina tiene

2. Para entender una versión especial de la autenticidad en los productos, ver el libro de Comaroff, J. L. y Comaroff, J. (2009).

3. Para esta y otras afirmaciones, ver «Rob Ford's most unforgettable quotes» (22 de marzo de 2016). City News. 
que ser virtuosa, mientras que líderes masculinos pueden tener toda clase de faltas -Silvio Berlusconi, por ejemplo, por no mencionar a Trump-).

Podría parecer que la sobreproducción de declaraciones escandalosas de Ford (lo de la cocaína fue la confesión más chocante, pero constantemente decía cosas que ningún político canadiense había dicho antes), esta producción constante de escándalo, socavaría el argumento de Adorno de que la jerga de la autenticidad se caracteriza por banales odas liberales al individualismo. Sin embargo, precisamente porque la autenticidad no tiene mucho contenido, creo que hay variedades no liberales o post-liberales de ella, cosa que a lo mejor no existía en la Alemania de Adorno. Sugiero que la autenticidad de Ford no consistía en lo que decía, en su mensaje, sino que, por el contrario, era él mismo, incluso como persona física, quien servía como representación de la autenticidad materializada. Su famosa gordura, creo, puede haber servido como signo de autenticidad (aunque al mismo tiempo sirviera para ponerle en ridículo entre sus críticos). La gordura puede servir como signo de autenticidad en una sociedad donde las clases altas hacen ejercicio, comen comida sana y van a yoga, como Justin Trudeau y su elegantísima mujer. Creo que no hay nada especialmente canadiense en el contraste entre la pareja Trudeau, los cosmopolitas perfectos, y las imágenes de signo totalmente opuesto del populista Rob Ford y su familia, familia que cuenta con varios políticos, todos gordos y todos de una masculinidad extrema.

El contraste en las posiciones sociales de diferentes actuaciones de autenticidad es importante. Ford era un hombre blanco, de derecha, pero sin gran lealtad a ningún partido; apenas educado, hizo carrera atacando a los cosmopolitas de Toronto que él y sus partidarios calificaban de «élites del centro» (downtown elites). Él, y en particular su cuerpo, reconocible en un segundo en las pantallas de televisión, representaban una actuación particularmente arriesgada de autenticidad.

El reconocimiento de vicios y defectos morales propios puede dar lugar al exilio político: Bill Clinton apenas sobrevivió a escándalos sexuales que habrían sido fácilmente ocultados o ignorados en la década de 1960, pero que en la década de 1990 se habían convertido en campos de minas. Hoy en día, mientras los líderes liberales respetables (como Trudeau) todavía necesitan probar su virtud, para los líderes conservadores o populistas es posible llegar al éxito con una masculinidad extrema que se aleja no sólo de las normas de igualdad y respeto, sino incluso de los buenos modales. Y este tipo de actuación es a menudo elogiada, porque, sean cuales fueren los defectos que los mismos políticos admiten, se considera que hablan y actúan desde el corazón, espontáneamente, sin influencia de los profesionales de las relaciones públicas y los asesores de imagen. (Dejaría para otra ocasión una reflexión pesimista sobre la visión hobbesiana o freudiana del ser humano, o por lo menos de 
los seres humanos masculinos, que se deja ver aquí-una visión que presupone que en el fondo a todos nos gusta ser impulsivos y agresivos, y si no podemos ser impulsivos y agresivos en el trabajo o en el hogar, o por lo menos no muy abiertamente, pues nos encanta ver, en las noticias, cómo alguien con más poder que nosotros se las arregla para continuar en el poder a pesar de romper abiertamente todas las normas «civilizadas»-. Esta sería la novela picaresca del populismo autoritario).

Como en todo el análisis político, se necesitan detalles locales adicionales para esbozar la forma particular de autenticidad representada por Ford, en comparación con otras figuras públicas masculinas en el Norte global. Y el sistema político municipal de Ontario es importante. Rob Ford había pasado muchos años como concejal municipal en un sistema que es muy individualista -en Ontario, los partidos políticos no tienen permitido, por ley, operar a nivel municipal-. Los concejales representan solo su distrito, y tienen que estar muy atentos a los mini-problemas de vecinos, pero no tienen que demostrar conocimientos sobre las crisis económicas y ecológicas de la ciudad entera; esos conocimientos incluso pueden ser vistos como algo negativo, como desatención a los vecinos y sus asuntos cotidianos. ${ }^{4}$ La frase «policy wonk» tiene un marcado signo negativo. Como Rob Ford no sabía nada ni del cambio climático ni de economía, ni le interesaba, se pasaba todo el tiempo hablando con vecinos y presentándose como el Superman que puede aterrizar en un hogar cualquiera y hacer llamadas telefónicas para que le atiendan en una oficina u otra del municipio. Así, pudo ser reelegido una y otra vez como concejal, sin apegarse a la ética local de la diversidad o a las normas locales sobre el discurso político, sin hacer nada más que ser él mismo: una persona auténtica que se interesaba por los mini-problemas de una $u$ otra familia, trabajo para el que los estudios de expertos más bien molestaban.

A lo largo de sus solitarios años en el concejo (votos del consejo de 39 a 1, con Ford como la única oposición, no eran infrecuentes), utilizaba un «habitus» ultra-populista que difería marcadamente de las formas educadas y moderadas de conservadurismo tradicional canadiense. Y mientras que otros políticos locales se esforzaban por mantenerse en buena forma física, elogiando el ciclismo y de vez en cuando retratándose en bicicleta, Ford se hizo famoso al proclamar que, si llegaba a alcalde, él pondría fin, personalmente, a la «guerra contra el automóvil».

No es casualidad que, incluso al llegar a alcalde, insistiera en conducir su propio vehículo (un enorme Suburban) en lugar de tomar el metro o usar el automóvil con chofer oficial. Para mucha gente, el gordo que conducía el gran automóvil ostentoso, 
fulminando contra los tranvías y las bicicletas, era claramente una figura «auténtica», posiblemente representando sus frustrados deseos personales.

Él y su familia representaban -y siguen haciéndolo, ahora sin él (murió de un cáncer en 2016) - todo lo contrario de la ciudad multicultural, educada, civilizada, compasiva y bien educada que ha sido durante mucho tiempo la imagen oficial de Toronto, y que sigue siendo la ideología dominante para los numerosos ciudadanos que eligen concejales moderados o de izquierda (Valverde, 2008). 5

Y en las elecciones municipales de 2010, los distritos más pobres y con más inmigrantes de la ciudad votaron en su mayoría por un hombre que actuaba igual que Trump, aunque sin utilizar el racismo de manera explícita (maniobra que hubiera sido desastrosa en una ciudad donde solo el $49 \%$ de la población es de raza blanca). Para esta forma de existir como ser político, el ser «uno mismo» equivale a despreciar los valores socialdemócratas y, en general, no solo a los expertos sino incluso los datos. Ford dijo lo que pensaba, en el momento, sin leer nada ni consultar a nadie; usó palabras que no se escuchaban nunca en la sociedad educada (incluyendo una referencia muy vulgar a relaciones sexuales con su esposa, hecha en su presencia), e hizo caso omiso de los consejos del personal y de su propio vicealcalde. Mientras que la educada y cosmopolita sociedad de Toronto se burló y se divirtió con Ford, él iba acumulando un tipo específico de capital político, definido precisamente por el contraste con las presentaciones del sí mismo preferidas por los políticos canadienses tradicionales, como Justin Trudeau.

El poder de un tipo de autenticidad personal cuyo contenido proviene en gran medida de una masculinidad popular anticuada y anti-intelectual, se convirtió notoriamente en un factor en las elecciones presidenciales de 2016 en Estados Unidos, y también en el Reino Unido en torno al Brexit. Desafortunadamente, esta fuerza cultural-política no ha dejado de ser significativa en la política canadiense: en junio de 2018, dos años después de la muerte prematura de Rob Ford, su hermano mayor, Doug Ford (cuya apariencia física y hábitos de consumo son extrañamente similares a los de su hermano, aunque no es tan espontáneamente escandaloso) se convirtió en el primer ministro de Ontario, la provincia más grande de Canadá, y con un gobierno mayoritario, a pesar de que muchas figuras conservadoras establecidas se opusieron abiertamente a su nominación. Al igual que su hermano Rob, Doug Ford ha hecho su carrera oponiéndose tanto a los consejos de expertos como a la

5. Mi libro Everyday Law on the Street: City Governance in an Age of Diversity (2012), contiene varias viñetas, extraídas de las notas de campo de los asistentes de investigación, en las que aparece Ford cuando aún era concejal, entre 2004 y 2008. Puesto que ya no se encuentra entre los vivos, creo que no hay una brecha en la ética de la investigación si digo aquí que el «Concejal Chevy» del libro, mal anonimizado a propósito, era en realidad Rob Ford. 
compasión «sensiblera» del estado de bienestar, en consonancia con el populismo masculino de derecha en todas partes.

Sin embargo, a diferencia de Doug, que todavía no ha aparecido borracho en público, Rob Ford disfrutaba beber y divertirse con personajes flagrantemente desacreditados, y tuvo que ser arrastrado de eventos públicos por su personal en algunas ocasiones en las que se presentó borracho y empezó a insultar e incluso a pegar a la gente. Estos comportamientos, paradójicamente, han ayudado a establecerlo como una figura política peculiarmente auténtica (una representación de autenticidad «warts and all»: «con sus defectos y todo», podríamos decir). La masculinidad es crucial aquí: ninguna mujer política, de derechas o de izquierdas, en ningún país, podría sobrevivir si se comportara como hizo Rob Ford. Y la raza también es importante, ya que es dudoso que cualquier político de ascendencia africana pudiera sobrevivir si se le asocia con borracheras y drogas ilegales, especialmente el crack.

¿Qué se puede aprender de la carrera política de Rob Ford sobre las prácticas actuales de decir verdad a nivel personal? Como explica el amplio informe del periodista Robyn Doolittle, si bien el haber admitido que consumía sustancias ilegales y el haber sido visto borracho en público condujo finalmente a su caída, aun así su desprecio por las reglas burocráticas y por la idea de que hay que consultar a expertos tocó cierta fibra sensible, especialmente en la clase trabajadora de Toronto - de todas las razas, hay que añadir (Doolittle 2014)-. Es poco probable que aquellas personas que se sintieron interpeladas como «Ford Nation», y que se congregaban para comer hamburguesas (una opción significativa de consumo) en lugares semi-suburbanos elegidos para las frecuentes barbacoas gratuitas de la familia Ford, escriban artículos de opinión en periódicos respetables. Por lo tanto, es difícil para una profesora universitaria saber si la etiqueta «auténtica» que muchos observadores le atribuyeron a Rob Ford describe con precisión la razón por la que esas personas se afiliaron a la familia Ford y a Rob Ford en particular. Pero para corroborar mi análisis de su popularidad, podríamos echar una mirada a los líderes masculinos en varios países tanto del Sur como del Norte global, donde una forma hipermasculina de populismo de derecha ha tenido éxito -aunque en otros países, aparte de Canadá, las actuaciones hipermasculinas de la política populista a menudo están profundamente entrelazadas con el racismo extremo-.

\section{Prácticas de la verdad, prácticas de sí}

La declaración más famosa de Ford como alcalde fue, sin duda, la ya citada «debo haber estado en uno de mis estupores de borracho» como explicación por haber 
fumado crack de cocaína. La lógica de la declaración tiene importancia. Mientras que hace cincuenta años estar borracho cuando se hacía algo a menudo daba lugar a un juicio menos severo, tanto por parte de los jueces como de la gente común, hoy en día el consumo excesivo de alcohol, especialmente por parte de un funcionario público, es un gran problema, incluso aunque no se cometan otros «malos» actos. El doble reconocimiento (de que no sólo fumó crack, sino que lo hizo en uno de sus muchos estados de embriaguez) parece la peor actuación política de la historia -a menos que reflexionemos sobre el estado actual de una forma de decir la verdad que Foucault denominó aveu o «confesión»-.

Las conferencias sobre la confesión y el decir verdad dictadas en Lovaina (Foucault, 2014) comienzan con una situación psiquiátrica, en la que un paciente de un manicomio de mediados del siglo XIX, es presionado y obligado a «confesar» que está realmente loco y que sus visiones son el producto de su imaginación-mediante repetidas duchas heladas administradas por el médico del asilo-. El ejemplo inicial de Foucault deja claro que la confesión no siempre es voluntaria: se puede acorralar a las personas para empujarlas a que confiesen su crimen o su locura (como ocurrió con Rob Ford, que sólo admitió la toma de cocaína cuando estaba claro que había salido a la luz un vídeo). Esta es una característica interesante de lo que Foucault llama aveu: es una revelación de una verdad sobre el sí mismo que es desagradable o que lo expone a uno al desprecio o al riesgo, pero que sea totalmente voluntaria o coaccionada no parece afectar su dinámica básica o la validez de la «verdad». (En eso se diferencia el aveu de la confesión católica, la cual se supone que es espontánea, no coaccionada).

El aveu es una conversación, no un texto; siempre es personal y contextualizada. El paciente de la historia de Foucault confesó su locura a su médico, no al mundo en general; y del mismo modo, la instancia paradigmática de la confesión explorada por Foucault en Lovaina como en las conferencias de Río, la historia de Edipo, también procede a través de interacciones específicas entre los diversos personajes, y entre los personajes y el público.

En las tragedias griegas antiguas, el coro desempeña un papel clave que podríamos llamar verificación. El coro juega el mismo papel (según Foucault) que los jurados desempeñarán más tarde en la justicia penal europea: actuando como uno, el coro reconoce y valida la «confesión» del protagonista. Así, para Foucault, el largo y retorcido camino que lleva a Edipo a ver que él es el criminal que persigue es un proceso que se desarrolla internamente, pero que luego tiene que ser validado o verificado por el coro, una verificación que sólo puede tener lugar después de la confesión. El coro reconoce y verifica la verdad jurídica, pero esa verdad tiene también que ser confesada por el propio criminal. Por lo tanto, no habría bastado con enviar 
un proto-detective para averiguar quién mató a Layo. Edipo, como el paciente en el manicomio francés, tiene que ser convencido, por sus propios descubrimientos y no por las palabras de un experto, hasta el punto de confesar que él mismo es el autor de los crímenes que propuso investigar.

Las verdades puramente fácticas -que el paciente es diagnosticado como demente; que Edipo sin saberlo mató a su padre- no son las verdades importantes en ninguna de las dos historias. Las afirmaciones importantes emergen a nivel personal, no a nivel fáctico, a medida que los personajes en cuestión declaran quiénes son ellos realmente, y en sus propias palabras. Las verdades personales, a diferencia de las verdades fácticas, unen la subjetividad de la persona que comete una falta a la verdad del «caso». Y la vinculación de las prácticas del sí mismo a las prácticas de la verdad no puede suceder en privado. La confesión tiene que ser certificada o validada por un público determinado.

En este contexto, y más directamente relacionada con la historia de Rob Ford, la insistencia de Alcohólicos Anónimos en que las personas que se unen a sus grupos tengan que confesar su vicio o enfermedad tanto a sus compañeros como a sí mismos, es un ejemplo muy relevante de la confesión contemporánea-una que prescinde de la poderosa autoridad médica de los manicomios del siglo XIX a favor de una situación más democrática, de grupo de pares-. Como he discutido en trabajos anteriores, A.A. insiste en la confesión, pero también insiste en que reconocer internamente el propio alcoholismo es insuficiente; el reconocimiento personal del problema debe ser inmediatamente seguido por una confesión semipública: «hola, soy fulanita de tal, y soy alcohólica» es saludo obligatorio en las reuniones de A.A. Hay que confesar no lo que uno ha hecho sino lo que uno es en el contexto específico de la reunión, no en cualquier lugar. En otras palabras, las prácticas del sí mismo de A.A. son personalizadas, son interactivas y dependen del lugar: sólo prácticas del sí mismo presenciales pueden unir la subjetividad de los bebedores a las «verdades» sobre el alcoholismo en general que se proclaman en los textos de A.A. (Valverde, 1998: capítulo 5).

\section{Género y geopolítica en la confesión: diferentes caminos a la autenticidad}

Para concluir, volvamos a Rob Ford y a las cuestiones de género y raza planteadas anteriormente. Hoy en día, las confesiones de figuras públicas sobre el consumo de drogas y alcohol son comunes. Sin embargo, no existe una forma única de confesión: las confesiones sobre drogas y alcohol (y las confesiones de mala conducta sexual) difieren de acuerdo a la presencia o ausencia de ciertas prácticas de sí mismo y de 
ciertas relaciones entre la persona oradora y su audiencia. No creo que exista un inventario de las formas contemporáneas de confesión, pero es posible extraer algunos rasgos distintivos de la confesión de Rob Ford. El punto más obvio es que la confesión de Ford no tomó la forma de asumir la identidad de adicto, como lo han hecho tantas figuras públicas estadounidenses cuando han sido atrapadas en situaciones embarazosas. De acuerdo con su epistemología completamente premoderna, Ford sistemáticamente rechazó la etiqueta de «adicto». En el momento en que se vio obligado a aceptar ir a un tratamiento residencial, él habló de sus «problemas» con el alcohol como algo innato, como el color de su cabello, pero enfatizando que tenía problemas con alcohol sin ser «un adicto».

Su rechazo del término «adicto» tenía probablemente su raíz en una teoría ya muy pasada de moda, según la cual «adicto» significa solamente drogadicto. Emborracharse regularmente es un comportamiento que alguien como Ford, criado en un hogar de clase trabajadora católica irlandesa en el período de la posguerra, vería como una debilidad o un defecto, pero no como un síntoma de una identidad desviada.

La presentación de Ford de sí mismo como un tipo normal que a veces bebe demasiado pero no posee una identidad desviada hubiera funcionado bien en los tribunales penales de los años 1940 o 1950s, cuando el consumo excesivo de alcohol contaba como un factor atenuante, sino una excusa (Valverde, 1998: capítulo 8). El consumo de alcohol es un problema social que no ha sido monopolizado por la medicina; lo que hizo Ford para perdonarse a sí mismo el consumo de crack no sería aceptado por ningún experto hoy, pero no es casualidad que Ford no quisiera saber nada de expertos, ni en asuntos de transporte público ni en asuntos personales.

En un momento dado, antes del escándalo del crack, el hermano Doug decidió forzar a Rob a perder peso -y Doug llevó una balanza al ayuntamiento, para que se pesara todas las semanas en público-. El rechazo abierto de Ford a ese plan premoderno y casi sádico de pérdida de peso (un plan que sugiere mucho sobre las prácticas de sí mismo de su hermano Doug, ahora gobernador de la provincia) parece haber ayudado a su puntuación de autenticidad (aunque es difícil aislar los efectos de un solo acto).

Podemos ver, por lo tanto, que la confesión de Ford sobre su «estupor de borracho» contenía toda una teoría de la relación entre el vicio, la identidad, el carácter y la responsabilidad, una teoría marcadamente opuesta a los discursos de los expertos, pero que tiene antecedentes venerables tanto en derecho penal como en discursos populares sobre el consumo de alcohol. Lo que muchas veces se llama ignorancia puede ser síntoma de la persistencia de epistemologías premodernas, epistemologías que van ligadas a ciertas prácticas de sí mismo y ciertos juegos de ética y verdad con mucha historia. 
Cuando el vicio, la virtud y el carácter están en juego, los regímenes de veracidad desplegados por expertos liberales a menudo fracasan, o simplemente son ignorados. Los datos y los informes no son las verdades que importan. En cambio, el demostrar una conducta política espontánea, siendo «fiel a uno mismo», depende de un aparato de autenticidad personal que (como mostró Foucault [2001; 2014]) es mucho anterior tanto al cristianismo como a la ciencia, y que parece resonar bien hoy entre los grupos que probablemente votarán por esas figuras masculinas populistas de derecha. ${ }^{6}$ Puede ser que figuras políticas más del centro no puedan movilizar fácilmente ideas antiguas sobre los pecados perdonables, pero los líderes populistas, por el contrario, o en cualquier caso los líderes populistas blancos y muy masculinos, como Putin o Trump, están operando abiertamente fuera del marco de la ética de cortesía, diversidad e inclusión. Ellos operan en un plano epistemológico y ético diferente.

El régimen de verdad moral que ve la embriaguez como un pecado perdonable y no un síntoma de una identidad desviada bien puede estar internamente conectado al régimen de verdad de la política populista, que se basa en el instinto, en los formatos de la industria del entretenimiento y en mitologías populares. La declaración de Ford de que terminaría con «la guerra contra el automóvil», en una ciudad donde las muertes de peatones y ciclistas han alcanzado proporciones epidemiológicas, encaja mejor de lo que puede parecer con la confesión sobre la cocaína. La autenticidad personal, para un cierto tipo de político populista, se logra y se acumula (como un capital político) sin referencia a ningún régimen de verdad «moderno». Y si uno puede confesar su pecado, en lugar de etiquetarse a sí mismo con una identidad desviada, entonces quizás algunas confesiones, con todos los riesgos políticos y personales que conllevan, puedan promover el proyecto político populista, un proyecto en el que las reglas de la formulación de políticas basadas en los datos están en cualquier caso suspendidas, por otras razones.

El reino de las afirmaciones de verdad personal es un campo epistemológico con ciertas características que pueden hacerse visibles principalmente por contraste, tanto con la ciencia como con la religión organizada. Pero si ciertas afirmaciones de verdad personal funcionarán para mejorar o para disminuir el capital político del orador es algo que depende no sólo de la habilidad personal, los caprichos del contexto y la pura suerte, sino también del tipo de factores que solíamos llamar estructurales.

6. Canadá no tiene un populismo de izquierda similar al español «Podemos» o el movimiento de cinco estrellas italiano. No es por lo tanto posible comparar a Rob Ford con populismos de izquierda locales. Pero investigaciones en otros lugares pueden complementar y quizá corregir el relato presentado aquí reflexionando sobre las diferencias y similitudes entre las prácticas del sí mismo de los populistas de izquierdas y las de los populistas de derechas. 
Los políticos populistas de todo el mundo son abrumadoramente masculinos, por lo que es difícil reunir una muestra suficientemente grande de mujeres para sacar conclusiones, pero las pocas políticas de derechas anti-expertos y anti-cosmopolitas que son mujeres (p. ej., Marine Le Pen) no se apartan del camino de la rectitud en su vida personal. O para decirlo de otra manera, la confesión puede ayudar a sumar puntos en la escala de la autenticidad personal sólo para ciertos grupos. Hace tiempo que sabemos que, en el capitalismo tardío, no existe una igualdad de condiciones económicas; pero las reflexiones sobre la confesión y la autenticidad presentadas aquí sugieren que tampoco existe una igualdad de condiciones éticas.

\section{Referencias}

ADORNO, T. (1973). The Jargon of Authenticity. Evanston: Northwestern University Press.

COMAROFF, J. L. y COMAROFF, J. (2009). Ethnicity, Inc. Chicago: The University of Chicago Press. DOOLITTLE, R. (2014). Crazy Town: the Rob Ford Story. Toronto: Penguin.

FOUCAULT, M. (1986). La verdad y las formas jurídicas. Barcelona: Gedisa. (200o). Truth and Juridical Forms. In J. Faubion (ed.), The Essential Works of Michel Foucault.

Vol. III. New York: New Press. (2001). Fearless Speech, ed. Joseph Pearson. Los Angeles: Semiotext(e) (2014). Wrong-doing, Truth-telling: the Function of Avowal in Justice, ed. Bernard Harcourt and

Fabienne Brion. Chicago: The University of Chicago Press/Presses Universitaires de Louvain. (2017). Discurso y verdad. Madrid: Siglo XXI.

LATOUR, B. (1999). Pandora's Hope. Essays on the Reality of Science Studies. Cambridge, MA: Harvard University Press.

(2004). Politics of Nature: How to Bring the Sciences into Democracy. Cambridge, MA: Harvard University Press.

ROSE, N. (1989). Governing the Soul: the Shaping of the Private Self. London: Routledge and Kegan Paul.

(1999). Powers of Freedom: Reframing Political Thought. Cambridge: Cambridge University Press.

VALVERDE, M. (1998). Diseases of the Will: Alcohol and the Dilemmas of Freedom. Cambridge: Cambridge University Press. 
(2003) Law's Dream of a Common Knowledge. Princeton: Princeton University Press.

(2008). The Ethic of Diversity: Local Law and the Negotiation of Urban Norms. Law and Social Inquiry, 33 (4), 895-924.

(2012). Everyday Law on the Street: City Governance in an Age of Diversity. Chicago: University of Chicago Press.

ZIZEK, S. (1991). For They Know Not What They Do: Enjoyment as a Political Factor. London: Verso. 